\title{
Second-person Perspective in Interdisciplinary Research: A Cognitive Approach for Understanding and Improving the Dynamics of Collaborative Research Teams
}

\author{
CLAUDIA E. VANNEY \\ Instituto de Filosofía, Universidad Austral, Argentina \\ cvanney@austral.edu.ar \\ ORCID: 0000-0001-6757-3119
}

\section{J. IGNACIO AGUINALDE SÁENZ}

Universidad Austral, Argentina

iaguinalde@austral.edu.ar

ORCID: 0000-0001-7026-6638

\begin{abstract}
In this paper, we argue that to reverse the excess of specialization and to create room for interdisciplinary cross-fertilization, it seems necessary to move the existing epistemic plurality towards a collaborative process of social cognition. In order to achieve this, we propose to extend the psychological notion of joint attention towards what we call joint intellectual attention. This special kind of joint attention involves a shared awareness of sharing the cognitive process of knowledge. We claim that if an interdisciplinary research team aspires to work collaboratively, it is essential for the researchers to jointly focus their attention towards a common object and establish a second-person relatedness among them. We consider some of the intellectual dispositions or virtues fostered by joint intellectual attention that
\end{abstract}


facilitate interdisciplinary exchange and explore some of the practical consequences of this cognitive approach to interdisciplinarity for education and research.

Keywords: interdisciplinary research; epistemic pluralism; intellectual collaborative work; social cognition; joint attention; second-person relatedness.

\section{Introduction}

As with the aim of universal peace on earth, today, it is almost undisputed that interdisciplinarity is of value and should be promoted. It is presumed that interdisciplinarity is a fruitful means by which to obtain new ideas, even in our own disciplines, as it assists in the improvement of social cohesion and communication, and it helps us become more intellectually complete. However, like universal world peace, interdisciplinary research is an aspiration that is rarely fulfilled.

There are several reasons for this lack of fulfilment. The volume of available data is overwhelming and mitigates our mastery of information, even within a single discipline. Furthermore, in the interdisciplinary research, new risks of possible mistakes arise, such as epistemic trespassing (Ballantyne 2019). In addition, the universalization of worldviews is inherent to many disciplines (or subdisciplines), not only with regard to content but also because many forms of disciplinary - and subdisciplinary- thinking are totalizing. Thus, there can be a lack of knowledge or willingness to learn about other worldviews and ways of thinking.

Nevertheless, some interdisciplinary research initiatives take place all around the world. Since 2010, for example, several research projects involving physicists, biologists, psychologists, neuroscientists, philosophers and theologians have been continuously developed in Argentina. Through these projects, the research teams have tried different ways to promote collaborative work between university scholars with diverse academic backgrounds.

The most paradigmatic result of these initiatives is the book $i$ Determinismo o Indeterminismo? Grandes preguntas de las ciencias a la filosofía [Determinism or Indeterminism? Big Questions from the Sciences to Philosophy] (Vanney and Franck 2016). Each of the eighteen chapters that con- 
stitute the book is focused on a question that simultaneously requires and exceeds a purely empirical approach, and is the object of study by a team comprising a scientist (a physicist, a biologist or a neuroscientist) and a philosopher. In this way, each chapter involved collaborations between coauthors who have, in the past, published in different domains. ${ }^{1}$ The dialogue between them reached a climax in three workshops that were held at Austral University (Argentina) in 2013, 2014 and 2015, but this dialogue was not limited to the workshops. Prior to the meetings, each pair of researchers began an exchange of ideas to prepare their presentations. During the workshop sessions, the various topics were discussed in depth. Finally, after the meeting, each pair of researchers continued working in collaboration until they assembled an integrated interdisciplinary document. This process required each pair of researchers to reach a heterogeneous conceptual consensus - in Hanne Andersen's words (Andersen 2010)- combining their individual knowledge to generate a cognitive output that they could not have produced alone. Thus, for at least a year, two researchers with different disciplinary training were encouraged to jointly focus their attention on a common question proposed to both.

This methodology of collaborative work faced a number of difficulties related to the interaction between specialists and the reciprocal evaluation of their different points of view. While the willingness of the researchers made it possible to successfully conclude the book, many of them later stated that the process of joint writing involved a much greater effort than initially planned. The intended interdisciplinary collaboration between philosophy and science admittedly challenged everyone, given that each researcher was used to work only within the framework of a theoretical doctrine with its own methods and procedures. The lack of knowledge of many empirical details challenged the philosophers, whilst the sophistication of the underlying philosophical discussions challenged

1 In a study carried out by Bergmann, Dale, Sattari, Heit and Bhat a metric for interdisciplinarity based on co-author publication history is proposed. They considered that "a published article that has co-authors with quite different publication histories can be deemed relatively "interdisciplinary," in that the article reflects a convergence of previous research in distinct sets of publication outlets” (Bergmann et al. 2017), 1412). 
the scientists. Moreover, since many terms change meaning according to the disciplinary context, the problem of communicating adequately proved to be considerable for all.

Experiences such as these confirm that interdisciplinary research is possible but not easy. Probably one of its main difficulties, and the cause of many others, lies in the fact that during the development of interdisciplinary research, many dissimilar cognitive methodologies are used.

Alister McGrath (2019) explored these difficulties in a recent book The Territories of Human Reason. Science and Theology in an Age of Multiple Rationalities. After distinguishing different modes of rationality and their attendant practices across disciplinary fields, he highlighted a key point: The "multiplicity of research methods leads to a corresponding plurality of perspectives or insights, which thus require to be integrated, coordinated, or colligated in order to allow the best possible overall representation of nature" (p. 210). He concluded the book with an open question: "How can we reverse the excesses of specialization and create room for interdisciplinary or transdisciplinary cross-fertilization?”, suggesting the following answer: "One route is through the cultivation of epistemic dependence, in which multiple thinkers bring about a shared expansion of a group's vision" (p. 226).

We expand upon that idea in this paper and propose a way to move from epistemic plurality towards a collaborative process involving social cognition. ${ }^{2}$ Since it's not the disciplines that actually dialogue, but individuals, in order to understand interdisciplinary work, we suggest deepening the study of one of the most basic dispositions that enable the development of interpersonal relationships or second-person relatedness: the psychological phenomenon of joint attention. We will examine this phenomenon and suggest extending it to a joint intellectual attention, to account for the dynamics of interdisciplinary research, and to explore

2 Social cognition focuses on the role played by cognitive processes in social interactions. According to Bodenhausen and Todd (2010) "social cognition researchers seek to identify the mental structures and processes that permit humans to navigate their social worlds successfully by understanding the psychological states (beliefs, emotions, goals, and so on) and traits (stable dispositions) of the persons they encounter and with whom they are interdependent" (p. 160). 
new paths to promote it. Thus, in the following sections, we propose and explain four theses:

1. Interdisciplinary research is a practice that, without denying the individual identity of the disciplines involved or pretending to transcend them, results in the production of new knowledge with insights from different fields. On the one hand, it is different from multidisciplinary research because it brings forth an integrated vision. On the other hand, it differs from transdisciplinary research because it avoids disciplinary integration achieved at a higher meta-level through a process of generalization.

2. The ultimate epistemic justification of the plurality of methodologies involved in interdisciplinary research is the cognitive richness of the human being, who is capable of exercising his or her rationality in many ways. Disciplinary training develops a specific set of cognitive resources in researchers. However, interdisciplinary research also demands the development of the ability to consider the topics from perspectives that are different from one's own. A process of social cognition among researchers of the work team facilitates this objective.

3. Because social cognition is built on the capacity to engage with other people's attention, we propose to extend the psychological notion of joint attention towards joint intellectual attention, offering a cognitive approach from a second-person perspective to understanding the dynamics of interdisciplinary research groups.

4. Joint intellectual attention fosters intellectual dispositions or virtues for interdisciplinary research.

We conclude this paper by considering some possible consequences of this cognitive approach to interdisciplinary research for education, teaching programs, researchers, and project planning. 


\section{What is interdisciplinary research?}

In the last fifty years, excessive specialization has exacerbated concerns related to the fragmentation of knowledge. In this context, international organizations, such as the OECD and UNESCO, have promoted a wider approach among researchers from different disciplines. The notions of multidisciplinarity, transdisciplinarity and interdisciplinarity, which are now common in academic fields and apply to both teaching and research, have developed as a result of this effort (Apostel et al. 1972; National Academy of Science 2005; Thompson Klein 2017). ${ }^{3}$

Although there is no single definition of these notions (Austin et al. 1996, Alvargonzález 2011), multidisciplinary work is characterized by the incorporation of contributions from various disciplines. During the development of a multidisciplinary research, researchers use the method of their own discipline to investigate an object in an autonomous way. The final result of this type of work broadens the horizon of information by incorporating a diversity of disciplinary contributions. But, because it consists of a juxtaposition of results obtained in an independent process, their conclusions lack a deep unity. In this juxtaposition, the disciplines remain clearly separate, and their original identities remain unquestioned. The treatment of the same question from diverse perspectives but in a consecutive way allows us to recognize the multidisciplinary character of this kind of research. That is, multidisciplinary research does not seek to integrate information but to give a comprehensive collection of information from different disciplines on a subject (Pohl, Truffer, and Hirsch Hardorn 2017, 322).

Transdisciplinary work, instead, represents the greatest degree of cross-disciplinary integration (Hall et al. 2017, 342). Transdisciplinary research creates new approaches to address a scientific problem based on a shared conceptual framework or on a unified system of axioms as a result of a global synthesis at a general meta-level, transcending the scope

3 In April 2018, the OECD published a position paper outlining the nature of the Future of Education 2030 project, including disciplinary and interdisciplinary knowledge. Cf. http://www.oecd.org/education/2030/oecd-education-2030-position-paper.pdf 
of disciplinary views. Transdisciplinary proposals are strong theoretical proposals which promote the application of a unique methodology, corresponding to a level of generality superior to that of the disciplines participating in the research, whereby their respective contributions are considered particular cases of the unifying metadiscipline. In other words, in transdisciplinarity, the results gain in integration and in generality, but disciplinary distinctions are lost in favour of a meta-level approach. Among the transdisciplinary proposals in science and philosophy we can include very different ones, such us diverse monistic unifications of an idealistic nature (Griffin 2008), or varied scientific reductionisms (De Ridder, Peels, and Woudenberg 2018).

In contrast, in interdisciplinary research, experts from different disciplines work in a joint, not independent, manner on a common problem. It is a research practice that, without denying the individual identity of the disciplines, nor pretending to transcend them, aims at the production of new knowledge thanks to the shared effort of academics with different backgrounds. The goal of interdisciplinary research is a harmonization of diverse thematic contents according to the cognitive level that is proper to each one of them. Consequently, the incorporation of disciplinary results in interdisciplinarity requires a delicate methodological discernment to avoid the research to conclude in naïve concordances, or in extrapolate statements that lack scientific rigor outside the field in which they were formulated. In this sense, interdisciplinarity differs from multidisciplinary research, on the one hand, because its objective is to achieve an integrated vision, and, on the other hand, it differs from transdisciplinary research because it avoids unifying the disciplines involved at a more general level.

According to Andersen (2016), specialty, discipline, or also subdiscipline is a community of scientists with highly similar expertise possessing basically the same set of cognitive resources that enable them to identify mostly the same problems and the same methods for their solution (p. 2). Miles MacLeod (2018) claims that, because specialization seeks to solve specific sets of problems in specific ways, a disciplinary vision makes it "difficult to see how another cognitive domain operates ef- 
fectively and efficiently in order to coordinate practices across domains, just as it makes it difficult to vary practices along the dimensions interdisciplinary work might require" (p. 716). This difficulty often leads to a certain impoverishment of one's own mental world, which psychologists have called hypocognition, with negative consequences for interpersonal and social relations (Wu and Dunning 2018).

MacLeod (2018) notes that studies on interdisciplinary research do not usually focus on its cognitive challenges, and in general we agree with him, but there are some remarkable exceptions. Andersen's proposal, for example, considers the degree of cognitive convergence and divergence as well as the degree of epistemic dependence among collaborators as the key dimensions for understanding the structure of contemporary science (Andersen 2016). Against this backdrop, she also describes and analyses four ideal types of research activities: the disciplinary legend (cognitive convergence and epistemic independence), the disciplinary division of labour (cognitive convergence and epistemic dependence), the interdisciplinary division of labour (cognitive divergence and epistemic dependence), and the omniscient genius (cognitive divergence and epistemic independence).

Analysing her ideal type of interdisciplinary division of labour, Andersen (2016) remarks that the "acquisition of the basic elements of the cognitive resources from another domain required for interlocking expertise implies some degree of simplification" (p. 4). Thus, when "the various contributions merely need to be juxtaposed there may be less mutual dependence between collaborators and only need for interlocking expertise on some isolated points" (p. 6). Nevertheless, when the individual contributions "derive from the application of divergent sets of cognitive resources, this requires additional interlocking expertise" (p. 6).

In our opinion, this point is the main difference between multidisciplinary and interdisciplinary research. The complex interaction of methodologies is not a relevant problem in multidisciplinary work because such work aims only to combine results from different sources to obtain conclusions. On the contrary, the requirement of important simplifications and interlocking expertise is a great challenge for interdisciplinary 
research to obtain an integrated vision. Such a vision requires the recognition that a plurality of cognitive methodologies is necessary to grasp a complex reality that has multiple dimensions of analysis.

\section{What is the epistemic justification of the plurality of methodologies involved in interdisciplinary research?}

The answer to this question is, at first glance, simple: The human being knows in many ways. Nevertheless, properly developing the content of this response requires a deep epistemic clarification. The vast literature of pluralism in the sciences is itself a testament to the epistemic importance of diverse methodologies not only across disciplines but even within the same field (Kellert, Longino, and Waters 2006; Lombardi and Ransanz 2011; Chang 2012).

Alister McGrath (2019) concludes his book, The Territories of Human Reason, noting the need for an ambitious explanation that could reconnect many fragmentary disciplinary insights to attain a cohesive account of our world. For him, it would be "to develop [...] a grand theory of human rationality, which is capable of accommodating such divergences across disciplines, and allowing them to be seen within a greater whole" (p. 225).

Among the attempts made in this direction, the work of the Spanish philosopher Leonardo Polo (1984-1996) stands out. According to Polo (1987), knowledge has two dimensions that fit perfectly with each other: One is the cognitive act (methodical dimension), and the other is the content known (thematic dimension). Thus, knowledge "is a unitary thematic act, or a theme that unitarily is an act" (p. 87). In other words, no theme appears without accounting for the intellectual method that leads to its consideration, and there is no intellectual act that does not delimit its theme in a precise manner. In his proposal, Polo discerns a diversity of cognitive acts, affirming that no cognitive level can be considered absolute. Vanney (2008) earlier discussed that a methodical-thematic pluralism such as Polo's allows us to lay the bases for establishing a congruent epistemic justification of the variety of scientific methodologies. 
In our view, both the diversity of cognitive acts and the requisite methodical-thematic adjustment allow a more in-depth analysis of the distinction among multidisciplinary, transdisciplinary, and interdisciplinary research. Multidisciplinary studies recognize a disciplinary diversity of methods and themes, i.e., the plurality of methodologies allow access to a certain type of knowledge. Nevertheless, because their results are limited to juxtaposing the thematic content of different cognitive values, they are unable to provide a unified vision. By contrast, transdisciplinary proposals promote the application of a unique integrative methodology at a meta level, allowing access to general knowledge with homogeneous cognitive value; but they do so at the cost of losing the distinctions between disciplines. Finally, interdisciplinary research recognizes the existence of a plurality of methodologies toward - thematic-knowledge of a complex multidimensional reality.

Returning to the question that guides this section, it is possible to conclude that the plurality of cognitive methodologies involved in interdisciplinary research obtains its ultimate justification in the cognitive richness of the human being who can exercise his or her rationality in many ways. This, in turn, correlates with a corresponding complexity of reality, which resists being described by a single method. Now, some individuals exercise specific mental operations more intensively than others. Beyond the basis of a certain natural predisposition, this preferred way of thinking is due to specific cognitive resources that are developed during early training in the profession, promoting the preferential use of some mental operations over others.

Specialization is good and necessary. Nevertheless, when a specific manner of disciplinary thinking is totalized, new risks of possible mistakes appear such as epistemic trespassing. In an excellent article, Nathan Ballantyne (2019) defines epistemic trespassers as "thinkers who have competence or expertise to make good judgments in one field but move to another field where they lack competence -and pass judgment, nevertheless" (p. 1). While undertaking cross-field efforts to enhance the understanding of fundamental questions, epistemic trespass is inevitable. Yet, a rigorous investigation demands that we do not trespass alone. We 
agree with Ballantyne's suggestion: "trespassing is a problem for individual thinkers, but it points toward social solution" (p. 25). Conducting interdisciplinary research alone is very risky. It is safer to perform this type of work with others.

\section{Joint attention: A cognitive approach to interdisciplinary research teamwork}

According to the Centre for Educational Research and Innovation of the OECD (Apostel et al. 1972), "an interdisciplinary group consists of persons trained in different fields of knowledge (disciplines) with different concepts, methods, and data and terms organized into a common effort on a common problem with continuous intercommunication among the participants from the different disciplines" (p. 25-26). That is, because a fruitful interaction between team researchers is necessary for the production of knowledge (Lattuca 2002), we should expect to find the relevant locus for examining such cognition-generating interactions within the field of social cognition.

Hence, a subject that may be exceptionally pertinent to this study is what psychologists call shared attention or joint attention, which involves two or more persons who share a common object of attention. Such activities are especially obvious in the development of the majority of young children, manifested in activities such as gaze-following, pointing, taking turns, and imitative behaviours. Many of these activities happen in the context of varieties of interpersonal play, for example, dancing.

Given that children spend so much time in such activities and given also that a lack of such engagement is often a cause of concern, ${ }^{4}$ the study of joint attention has become a topic of considerable interest among many developmental psychologists, evolutionary psychologists, and, more recently, philosophers and theologians interested in intersubjectivity (Eilan et al. 2005, Seemann 2012, Metcalfe and Terrace 2013). Plausible ar-

4 For example, numerous studies indicate the deficit of joint attention as a differential element of autistic spectrum disorder (Adamson et al. 2019). 
guments have recently been advanced that joint attention plays a crucial role in human cognitive, social, emotional and linguistic development. ${ }^{5}$

Although the experience of joint attention is commonplace, a satisfactory and precise definition is nevertheless challenging. Some psychologists as Butterworth (1991) have defined joint attention as the simple ability to follow the gaze of another person or "looking where someone else is looking” (p. 223). This definition accentuates the perceptive stance as joint attention specifically means joint visual attention. ${ }^{6}$ Others, however, have proposed a more specific definition, noting that those who share the same goal in an interrelation focus not only on the same object but also attend to the behaviour of their co-attender to accommodate him or her (Tomasello 2014). The practice of a team sport is a good example of the attention paid to the way in which others are performing. In soccer, the person who plays as a goalkeeper not only pays attention to the ball, but also to the expression and attitude of the other persons trying to score a goal.

For this paper, we have adopted a definition advanced by Peter Hobson (2005) who conducted many studies of the behaviour of typical and atypical children. In Hobson's words, joint attention implies that one should "share awareness of the sharing of the focus, something that often entails sharing an attitude towards the thing or event in question" (p. 185). Both commonplace experience, and this definition, draw attention to an alignment of stance between two persons in joint attention, an alignment that Naomi Eilan (2005) referred to as a "meeting of minds", (p. 1).

Following Hobson, Axel Seemann (2007) uses a similar definition, specifically, that "instances of joint attention to an object are characterized not only by subjects' joint focus on an object, but typically also by an alignment of their respective subjective attitudes" (p. 228). According to Seeman, this joint attention is also the context within which there is an emergence of the "we" perspective. This perspective is not produced by

5 Carpendale and Lewis (2006) even stated "that human forms of cognition are built on the capacity to engage with other people's attention. This provides the foundation for language and forms of cognition resulting from the internalization of communicative interaction" (p. 253).

6 Several empirical studies, such as (Emery et al. 1997), have operationalized joint attention in this way. 
a specific interrelation between the perspectives of the "I", but it is constituted on a more primitive level, making possible the joint search of objectives, goals and desires.

Once there is this intersubjective "we" perspective, there is the possibility of what can be called joint action. ${ }^{7}$ Again, according to Seemann, "the capacity to engage in this mode of action can be seen as a particular kind of knowledge: a practical skill that enables jointly engaged persons to act together" (p. 229). To explain what makes the joint action possible, Seemann notes that different schools of thought focus on diverse aspects of the jointness-enabling psychological states: joint attention (perceptual focus), collective intentionality (intentional focus), and common knowledge (epistemic focus). He argues, however, that the perceptual aspect enjoys a privileged status and can be easily invoked to understand the other two. ${ }^{8}$ Hence, Seemann, along with others, ${ }^{9}$ considers the phenomenon of joint attention to be the primary and the most appropriate starting point for explaining joint action.

Given that research team work is a kind of joint action (an intellectual one), the analysis above suggests that we should look to joint attention as the primary and most important starting point for understanding successful instances of such work. There seems to be a clear parallelism: there is a common object of attention, specifically, the area under common investigation, and there are two or more people commonly attending. This parallelism can then be applied both to multidisciplinary and interdisciplinary research, although differently in each case.

In the above section, we noted that two dimensions of knowledge can be distinguished: the thematic dimension and the methodical dimension. Following this distinction, in multidisciplinary work we may understand

It should be noted that accounts of joint attention and joint action remain somewhat difficult to interpret and relate at the present time as the studies of joint attention and joint action have formed surprisingly independent literatures (Milward and Carpenter 2018).

8 The relationship between joint attention and common knowledge is analyzed in (Campbell 2005, Peacocke 2005).

9 Böckler and Sebanz (2013), for example, claim that joint action and joint attention are "tightly linked in social interaction. In fact, successful joint action crucially depends on joint attention” (p. 208). 
that joint attention implies that researchers share the awareness of sharing disciplinary content. That is, in multidisciplinary research knowledge is shared in its thematic dimension.

In interdisciplinary work, however, there is or should be a special and deeper kind of joint attention involving a shared awareness of sharing the cognitive process of knowledge. When one shares intellectual work with a researcher from another discipline one also learns, to a certain extent, to think in the way he or she does. That is, in interdisciplinary research knowledge is shared in its methodical dimension, not only in its thematic dimension. This specific shared awareness deserves a special name. We shall call it joint intellectual attention.

O’Madagain and Tomasello (2019) consider "joint attention to mental content" to be a process that operates on a second level, transforming the simpler joint attention of which infants and apes are capable into the mature process in which adults engage. We claim that something similar happens with joint intellectual attention. Yet, while "joint attention to mental content" regards to the thematic dimension of knowledge, joint intellectual attention regards to the methodical one.

The experience of working interdisciplinarily with several teams of scientists and humanists over the last ten years - which culminated in the publication of the book ¿Determinismo o indeterminismo? mentioned earlier - has shown us that, in successful interdisciplinary groups, researchers are intellectually moved by others to think in ways in which they are not accustomed. This intellectual movement stimulates previously latent and undeveloped modes of rationality, associated with intellectual habits that are unusual in each researcher's own disciplinary field. This notion of being "moved" by others in a non-physical manner has already been noted. Andrew Pinsent (2012) argues that the phenomenon of joint attention is particularly correlated with "the ability to be 'moved' by others and to relate to others in a specifically second-personal sense" (p. 49). If we refer this consideration to interdisciplinary research, we may say that, when academics with diverse disciplinary backgrounds sustain a joint intellectual attention in the course of an investigation, they mutually motivate each other to think in ways different from their own. This awakening of latent 
cognitive capacities does not occur as a result of systematic training, but rather as a result of thinking together.

To summarize, in interdisciplinary exchange between, for instance, science and philosophy, scientists do not merely contribute with data and theorizations and philosophers with integrated understandings and conceptual clarifications. The core of truly interdisciplinary research requires not only the learning of new content from a different discipline but also the learning of new ways of thinking. By sharing the awareness of shared ways of thinking, interdisciplinary researchers are moved to consider topics with methodologies different than their own. Openness to the ways in which other researchers think requires leaving the intellectual sphere where each one operates with confidence. It is an effort that is rewarded with an expansion of one's own rationality. This capacity for openness is latent in every person and is never lost. It corresponds to human nature and is rooted in a deep desire for truth that is found in everyone. In this way, interdisciplinary work enriches researchers' cognitive resources and corrects the typical hypocognition of individual approaches. ${ }^{10}$

\section{Intellectual dispositions or virtues fostered by joint intellectual attention}

Joint attention has important consequences for the development of social cognition in young children. In the same way, just as ordinary joint attention accompanies the biological development of the person, joint intellectual attention requires a sufficiently prolonged time for maturation.

In this section, we will propose three parallelisms between ordinary joint attention and joint intellectual attention that will make it possible to discern a series of epistemic dispositions - or intellectual virtues - that consolidate the second-person relatedness among researchers. They are thus highly relevant for collaborative intellectual work in general, and

10 Andersen and Wagenknecht (2013), for example, argue, that "knowledge resulting from interdisciplinary collaboration builds to varying degrees on shared mental models and conceptual structures and is therefore possessed to varying degrees by individual group members and the group as a whole” (p. 1896). 
specially for the successful performance of an interdisciplinary team in particular.

First, the phenomenon of joint attention was initially studied by developmental psychologists interested in understanding the preverbal and early verbal development of vocabulary. Tomasello (1999), for example, explained that children "learn new words best in joint attentional scenes that are socially shared with others" (p. 109-110). Similarly, we suggest that joint intellectual attention allows a gradual construction of a common interdisciplinary language among scholars with different expertise. Such a language is richer than that of individual researchers; however, it is not based on the mere sum of technical terms but rather on acknowledgement of the different meanings that the same word can have in diverse disciplinary fields. Acquiring this common language is not a minor issue, but the first absolutely necessary step for interdisciplinary work.

Second, human beings are capable of assuming perspectives different from their own. Thus, they can understand how others perceive, think and feel. In the mature adult, this capacity can even go beyond the mere determination of a person's point of view at a given moment as he or she can also understand that the same thing can be interpreted according to the point of view of a person's different dimensions (vision-spatial, epistemic, conceptual, and affective). Psychologists have claimed that to develop perspective-taking, human children first learn about perspectives within the context of joint attentional engagement (Moll and Meltzoff 2011, 2012). Similarly, we suggest that joint intellectual attention helps researchers to recognize the different approaches that frame their contributions. This implies, in turn, the recognition that the diverse methodologies used in this type of research can also refer to different dimensions of the same reality.

Third, several philosophers have also noted that joint attention plays a fundamental role in grasping the other's mind, and it is thus a capacity that enables understanding other people (Heal 2005, Roessler 2005). While much research on joint attention assumes a cognitive perspective, Hobson (2005) suggested that joint attention is based on "a special form of interpersonal engagement involving feelings” (p. 188). He also empha- 
sized the importance of joint attention in the development of the interpersonal coordination of affectivity (Hobson 1989). Böckler and Sebanz (2013) explain that "social-affective accounts have stressed the role of sharing attention for the development of understanding others as having mental states. According to these accounts, joint attention, by fostering the sharing of emotional states, also underlies the development of joint action capabilities" (p. 211). Similarly, we suggest that joint intellectual attention contributes to an appreciation of, and mutual respect among, the members of the research team, promoting an attitude of openness and trust among them that consolidates the desire to learn from others.

Moreover, ordinary human experience also commends the need to protect this attitude of openness and trust from the kind of self-sufficiency and closure associated with intellectual pride. Pride blocks relationships with others that enable one to be moved to have new insights (Pinsent (2012), 77-82). By contrast, in order to collaborate interdisciplinarily it must be assumed that one person cannot encompass everything. This disposition lays the foundation for the epistemic virtue of intellectual humility. As Craig Boyd (2017) has observed, "intellectual humility requires more than the simple application of the rules of logic, but also a perspective that demands the recognition of one's own limitations and prejudices" (p. 173). Therefore, the virtue of intellectual humility guarantees an attitude of constant openness to learn something new, both from one's own discipline and from others. It is an essential epistemic virtue to avoid the risks of hypocognition and epistemic intrusion, and to continually broaden our knowledge.

\section{Final discussion}

In this paper, we claim that if an interdisciplinary research team aspires to work in collaboration, it is essential for researchers to jointly focus their attention on a common subject, establishing a second-person relatedness among them. In our view, creative pluralism in interdisciplinary research requires to share the way of thinking of others, and not only to learn new content from different fields. Only in this manner can interdisciplinary exchange succeed. 
In this final discussion, we want to consider some practical consequences of the cognitive approach to interdisciplinary research proposed in this paper.

Consequences for education: As mentioned above, collaborative work is the best approach to integrating, coordinating or harmonizing disciplinary information to allow the most fully possible overall representation of nature. As in any collaborative process, joint intellectual attention not only promotes but also requires some attitudinal and ethical dispositions in researchers such as appreciation, mutual respect, openness and confidence. These dispositions are habits that must be rooted in people from an early age. Promoting these virtues in children and adolescents is, in our opinion, the best way to educate future interdisciplinary researchers. Considering the difference between interdisciplinarity and multidisciplinarity noted above, it is easily concluded that interdisciplinarity is not encouraged by providing students with information on multiple areas of knowledge but by preparing young people such that they can interact with specialists in different subjects in the future. Preparation for interdisciplinary research should focus more on openness to others than on opening to multiple themes.

Consequences for teaching programs: Interdisciplinary integration requires that each member of the research team possesses solid prior disciplinary training and experience. Only when scholars have in-depth expertise in their own discipline can they share their cognitive resources with others during an investigation that requires joint intellectual attention. That is, because interdisciplinary exchange compels a demanding secondpersonal cognitive process, it cannot be accomplished if each researcher has not previously achieved cognitive development in a specialty. Therefore, it is easily concluded that the premature promotion of a variety of simultaneous studies at a superficial level will not be the best approach to developing interdisciplinarity. If young people have not yet cognitively matured in some discipline, encouraging a mixed group of students to perform a superficial synthesis about a plurality of ideas will only result in juxtaposition without unity. 
Consequences for researchers: Because some people are unable to undertake the effort of joint intellectual attention, interdisciplinary research is not for everybody. Each individual must work in the manner in which he or she works best. "Autistic" researchers (or investigators who metaphorically lack an integrative framework in their research approach) work best in disciplinary research. Doing so, however, does not necessarily imply a loss because, as noted above, interdisciplinary research is grounded in disciplinary research. There is no "interdiscipline" without disciplines.

Consequences for project planning: Because interdisciplinary research is intellectual work, it is not a simple consequence of a voluntary decision but rather a result of an intellectual motivation. For a group of researchers to undertake the challenge of joint intellectual attention, it is insufficient to proceed based only on their decisions to join a project. Offering them an intellectually thought-provoking proposal that stimulates their intelligence and encourages them to overcome the difficulties inherent in interdisciplinary work is absolutely necessary. In this sense, developments in educational policy that promote interdisciplinary research are necessary to facilitate the work of existing interdisciplinary teams. Nevertheless, the motivating force that gives birth to new projects will not come from them. The origin of a novel collaborative project mainly requires an inspiring idea that encourages others. Another important issue to consider in project planning is that achieving joint intellectual attention among specialists takes time, as it does with the acquisition of any intellectual virtue. A first collaborative project can be a good initial trigger; however, it will probably be necessary to maintain joint work on several projects until it is achieved.

We want to finish this article with a methodological comment. In this work, we presented an analysis of interdisciplinary research that derives from the concept of joint intellectual attention. This notion is mainly based on our practical experience and developed gradually over the last ten years from observations of the interdisciplinary work of several teams of scientists and humanists. That work revealed the importance of second-personal relatedness to interdisciplinary research.

The theoretical support of joint intellectual attention in this paper is drawn from an analogy with joint attention in the psychology of joint ac- 
tion. By suggesting possible extensions of theoretical concepts and ideas, analogies are widely recognized as playing an important heuristic role, as aids to discovery and by guiding conceptual development (Bartha 2019). Yet, analogies also have limits. The psychological literature on joint attention mainly deals with very low-level tasks such as watching the same object, while joint intellectual attention deals with academic research, on the other side of the cognitive spectrum. The use of analogy in this work does not pretend to fill this gap, but to seek the foundations of interdisciplinary research in the more basic disposition that enables the development of interpersonal relationships.

Furthermore, though joint intellectual attention involves both a motivational and a success component, as do intellectual virtues on a responsibilist perspective (Zagzebski 1996), this disposition could be conceived as an intellectual virtue of intellectual endeavours in general. If so, the case of interdisciplinary research would be just a paradigmatic context in which we could see the benefits of forming and cultivating it. To go further in this direction, however, would be the topic of other studies.

Moreover, because the ideas proposed in this paper have significant practical consequences, especially for decision making in educational institutions, it would be useful if joint intellectual attention could also be empirically tested by cognitive psychologists. Such testing would constitute in itself a good interdisciplinary research.

\section{Acknowledgements}

This project was made possible through the support of grants from the Universidad Austral (Título del Proyecto: Epistemología de la investigación interdisciplinar entre filosofía y ciencias - ID: 2019-IFUA-EPI04) and from the John Templeton Foundation (The Launch of MA \& PhD Degrees in Philosophy and the Foundations of Science for Latin America - ID: 61347). The opinions expressed in this publication are those of the authors and do not necessarily reflect the views of the Universidad Austral or the John Templeton Foundation. 


\section{References}

Adamson, Lauren B., Roger Bakeman, Katharine Suma, and Diana L. Robins. 2019. “An Expanded View of Joint Attention: Skill, Engagement, and Language in Typical Development and Autism." Child development 90 (1):e1. DOI: 10.1111/cdev.12973.

Alvargonzález, David. 2011. “Multidisciplinarity, Interdisciplinarity, Transdisciplinarity, and the Sciences.” International Studies in the Philosophy of Science 25 (4): 387-403. DOI: 10.1080/02698595.2011.623366.

Andersen, Hanne. 2010. “Joint Acceptance and Scientific Change: A Case Study.” Episteme 7 (3): 248-265. DOI: 10.3366/epi.2010.0206.

Andersen, Hanne. 2016. "Collaboration, interdisciplinarity, and the epistemology of contemporary science." Studies in History and Philosophy of Science 56: 1-10. DOI: 10.1016/j.shpsa.2015.10.006.

Andersen, Hanne, and Susann Wagenknecht. 2013. "Epistemic dependence in interdisciplinary groups.” Synthese 190: 1881-1898.

Apostel, L., G. Berger, A. Briggs, and G. Michaud. 1972. Interdisciplinarity problems of teaching and research in universities. Washington: OECD Publication Center.

Austin, Timothy R., Alan Rauch, Herbert Blau, George Yudice, Sara van Den Berg, Lillian S. Robinson, Jacqueline Henkel, Timothy Murray, Mark Schoenfield, Valerie Traub, and Marianna de Marco Torgovnick. 1996. "Defining Interdisciplinarity.” PMLA 111 (2): 271-282. DOI: 10.2307/463106.

Ballantyne, Nathan. 2019. “Epistemic Trespassing.” Mind 128 (510): 367-395. DOI: $10.1093 / \mathrm{mind} / \mathrm{fzx} 042$.

Bartha, Paul. 2019. Analogy and analogical reasoning. In The Standford encyclopedia of philosophy, edited by Edward N. Zalta. https://plato.stanford.edu/archives/spr2019/entries/reasoning-analogy/.

Bergmann, Till, Rick Dale, Negin Sattari, Evan Heit, and Harish S. Bhat. 2017. "The Interdisciplinarity of Collaborations in Cognitive Science." Cognitive Science 41: 1412-1418.

Böckler, Anne, and Natalie Sebanz. 2013. "Linking Joint Attention and Joint Action.” In Agency and Joint Attention, 206-215.

Bodenhausen, Galen V., and Andrew R. Todd. 2010. “Social cognition.” Wiley Interdisciplinary Reviews: Cognitive Science 1 (2): 160-171. DOI: 10.1002/wcs.28.

Butterworth, G. E. 1991. "The ontogeny and phylogeny of joint visual attention.” In Natural theories of mind: Evolution, development and simulation of everyday mindreading, edited by A. Whiten, 223-232. Oxford: Blackwell. 
Campbell, J. 2005. “Joint attention and common knowledge.” In Joint Attention: Communication and Other Minds, edited by Naomi Eilan, Christopher Hoerl, Teresa McCormack and Johannes Roessler, 287-297. Oxford: Oxford University Press.

Carpendale, J., and C. Lewis. 2006. How children develop social understanding. Oxford: Blackwell.

Chang, Hasok. 2012. Is water H2O: evidence, realism and pluralism, Boston studies in the philosophy of science; v. 293. Dordrecht: Springer.

De Ridder, Jeroen, Rik Peels, and René van Woudenberg. 2018. Scientism: Prospects and Problems. New York: Oxford University Press.

Eilan, Naomi. 2005. “Joint attention, communication and minds." In Joint attention: Communication and other minds. Issues in philosophy and psychology, edited by Naomi Eilan, 1-33. Oxford: Clarendon Press ; New York : Oxford University Press.

Eilan, Naomi, Christopher Hoerl, Teresa McCormack, and Johannes Roessler, eds. 2005. Joint Attention: Communication and Other Minds. Oxford: Oxford University Press.

Emery, Nathan, Erika Lorincz, David Perrett, Michael Oram, and Christopher Baker. 1997. "Gaze Following and Joint Attention in Rhesus Monkeys ("Macaca mulatta”)." Journal of Comparative Psychology 111 (3):286. DOI: 10.1037/07357036.111.3.286.

Griffin, David Ray. 2008. "Interpreting science from the standpoint of Whiteheadian.” In The Oxford Handbook of Religion and Science, 453-471. Oxford University Press.

Hall, Kara L., Brooke A. Stipelman, Amanda L. Vogel, and Daniel Stokols. 2017. "Understanding cross-disciplinary team-based research." In The Oxford Handbook of Interdisciplinarity, edited by Robert Frodeman, 338-356. Oxford: Oxford University Press. Original edition, 2010.

Heal, Jane. 2005. "Joint Attention and understanding the mind." In Joint Attention: Communication and Other Minds, edited by Naomi Eilan, Christopher Hoerl, Teresa McCormack and Johannes Roessler, 34-44. Oxford: Oxford University Press.

Hobson, Peter. 1989. “On sharing experiences.” Development and Psychopathology 1 (3):197-203. DOI: 10.1017/S0954579400000390.

Hobson, Peter. 2005. "What Puts the Jointness into Joint Attention?” In Joint attention: Communication and other minds. Issues in philosophy and psychology, edited by Naomi Eilan, Chrisoph Hoerl, Teresa McCormack and Johannes Roessler, 185-214. Oxford: Oxford University Press. 
Kellert, S. H., H. E. Longino, and C. K. Waters, eds. 2006. Scientific Pluralism. London: University of Minnesota Press.

Lattuca, Lisa R. 2002. "Learning Interdisciplinarity: Sociocultural Perspectives on Academic Work.” The Journal of Higher Education 73 (6): 711-739.

Lombardi, O., and A. R. P. Ransanz. 2011. "Lenguaje, ontología y relaciones interteóricas: en favor de un genuino pluralismo ontológico.” Arbor-Ciencia Pensamiento Y Cultura 187 (747): 43-52. DOI: 10.3989/arbor.2011.747n1005.

MacLeod, Miles. 2018. "What makes interdisciplinarity difficult? Some consequences of domain specificity in interdisciplinary practice.” Synthese 195: 697-720.

McGrath, Alister E. 2019. The Territories of Human Reason: Science and Theology in an Age of Multiple Rationalities, Ian Ramsey Centre studies in science and religion. Oxford: Oxford University Press.

Metcalfe, J., and H. Terrace, eds. 2013. Agency and joint attention. Oxford: Oxford University Press.

Milward, Sophie J., and Malinda Carpenter. 2018. "Joint action and joint attention: Drawing parallels between the literatures." Social and Personality Psychology Compass 12 (4):n/a-n/a. DOI: 10.1111/spc3.12377.

Moll, H., and A.N. Meltzoff. 2011. "Perspective-Taking and its foundation in joint attention.” In Perception, Causation, and Objectivity, edited by Naomi Eilan, Hemdat Lerman and Johannes Roessler, 286-304. Oxford: Oxford University Press.

Moll, H., and A.N. Meltzoff. 2012. "Joint attention as the fundamental basis of understanding perspectives." In Joint attention. New developments in psychology, philosophy of mind, and social neuroscience, edited by Axel Seemann. Cambridge (MA): MIT Press.

National Academy of Science, US. 2005. Facilitating Interdisciplinary Research. Washington DC: The National Academies Press.

O’Madagain, Cathal, and Michael Tomasello. 2019. "Joint attention to mental content and the social origin of reasoning." Synthese. DOI: 10.1007/s11229019-02327-1.

Peacocke, A. R. 2005. “Joint attention: Its nature, reflexivity and relatio to common knowledge." In Joint Attention: Communication and Other Minds, edited by Naomi Eilan, Christopher Hoerl, Teresa McCormack and Johannes Roessler. Oxford: Oxford University Press.

Pinsent, Andrew. 2012. The Second-Person Perspective in Aquinas's Ethics. Virtues and Gifts. New York: Routledge. 
Pohl, Christian, Bernhard Truffer, and Gertrud Hirsch Hardorn. 2017. "Addressing wicked problems throught transdisciplinary reserach." In The Oxford Handbook of Interdisciplinarity, edited by Robert Frodeman, 318-331. Oxford: Oxford University Press. Original edition, 2010.

Polo, Leonardo. 1984-1996. Curso de Teoría del Conocimiento. Tomos I a IV. Pamplona: Eunsa.

Polo, Leonardo. 1987. Curso de Teoría del Conocimiento. Tomo I. 3 ed. Pamplona: Eunsa. Original edition, 1988.

Roessler, Johannes. 2005. "Joint attention and the problem of other minds." In Perception, Causation, and Objectivity, edited by Naomi Eilan, Hemdat Lerman and Johannes Roessler, 230-259. Oxford: Oxford University Press.

Seemann, Axel. 2007. "Joint Attention, Collective Knowledge, and the "We" Perspective.” SocialEpistemology21(3):217-230.DOI:10.1080/02691720701673959.

Seemann, Axel, ed. 2012. Joint attention. New developments in psychology, philosophy of mind, and social neuroscience. Cambridge (MA): MIT Press.

Thompson Klein, J. 2017. Typologies of interdisciplinarity: The boundary work of definition. In The Oxford Handbook of Interdisciplinarity, edited by Robert Frodeman. Oxford: Oxford University Press.

Tomasello, Michael. 1999. The cultural origins of human cognition. Cambridge, Mass. ; London: Harvard University Press.

Tomasello, Michael. 2014. “Joint attention as social cognition.” In Joint attention: Its origins and role in development, edited by C. Moore and P. Dunham, 103-130. New York: Psychology Press.

Vanney, Claudia E. 2008. Principios Reales y Conocimiento Matemático. La Propuesta Epistemológica de Leonardo Polo. Pamplona: Eunsa.

Vanney, Claudia E., and Juan F. Franck, eds. 2016. ¿Determinismo o indeterminismo? Grandes preguntas de las ciencias a la filosofía. Vol. 4, De las ciencias a la filosofía. Rosario: Ediciones Logos

Universidad Austral.

Wu, Kaidi, and David Dunning. 2018. "Hypocognition: Making sense of the landscape beyond one's conceptual reach.” Review of General Psychology 22 (1): 25-35. DOI: 10.1037/gpr0000126.

Zagzebski, Linda Trinkaus. 1996. Virtues of the mind: an inquiry into the nature of virtue and the ethical foundations of knowledge. Cambridge: Cambridge University Press. 